\title{
FEASIBILITY OF PRODUCING JET FUEL FROM GPGP BY-PRODUCTS
}

\author{
Quarterly Technical Progress Report \\ for the period \\ May 17, 1987 - August 16, 1987 \\ Project Manager: W.G. Willson \\ Principal Investigators: W.G. Willson, UNDERC \\ C.L. Knudson, UNDERC \\ J.R. Rindt, UNDERC
}

Work Performed Under Contract No. DE-AC22-87PC90016

For

U.S. Department of Energy

Office of Fossil Energy

Pittsburgh Energy Technology Center

Pittsburgh, Pennsylvania

By

University of North Dakota Energy Research Center Grand Forks, North Dakota

\section{MASTER}




\section{DISCLAIMER}

This report was prepared as an account of work sponsored by the United States Government. Neither the United States nor any agency thereof, nor any of their employees, makes any warranty, express or implied, or assumes any legal liability or responsibility for the accuracy, completeness, or usefulness of any information, apparatus, product, or process disclosed, or represents that its use would not infringe privately owned rights. Reference herein to any specific commercial product, process or service by trade name, mark, manufacturer, or otherwise, does not necessarily constitute or imply its endorsement, recommendation, or favoring by the United States Government or any agency thereof. The views and opinions of authors expressed herein do not necessarily state or reflect those of the United States Government or any agency thereof.

\section{TECHNICAL STATUS}

This technical report is being transmitted in advance of DOE review, and no further dissemination or publication will be made of the report without prior approval of the DOE Project/Program Manager. 


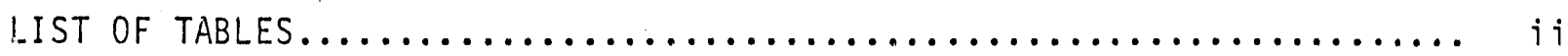

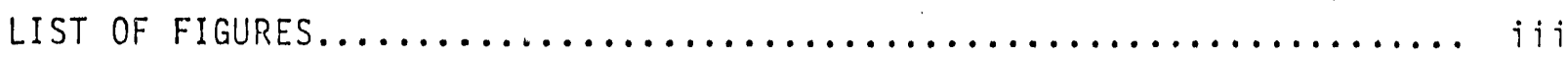

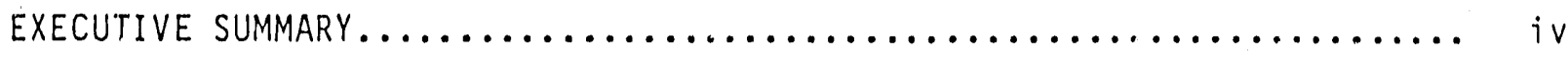

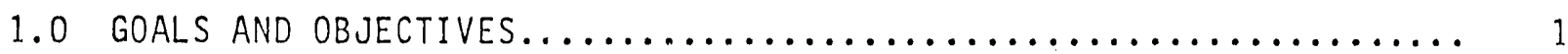

2.0 TASK 1 - FEEDSTOCK CHARACTERIZATION........................ 2

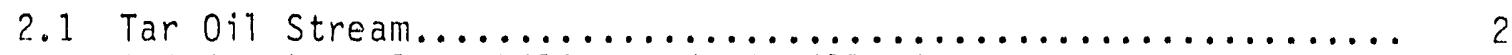

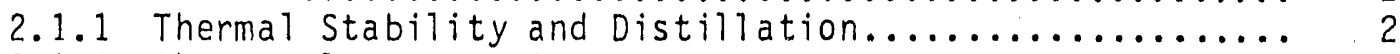

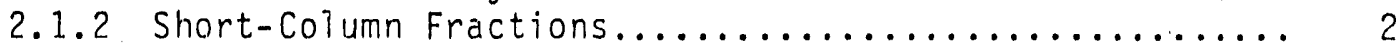

2.1.3 Acid-Base-Neutral Fractions.................... 8

3.0 TASK 2 - REACTION INVESTIGATIONS/PRODUCT ANALYSES ............. 8

3.1 Staged Processing.............................. 8 


\section{LIST OF TABLES}

Title

Page

1. ELEMENTAL ANALYSIS OF TAR OIL TOTAL AND COLUMN FRACTIONS ........... 6

2. HYDROGEN DISTRIBUTION NMR ANALYSIS OF TAR OIL COLUMN FRACTIONS....... 6

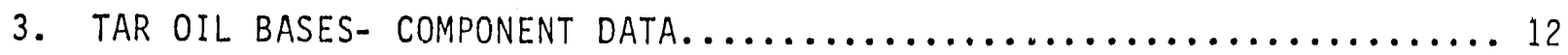

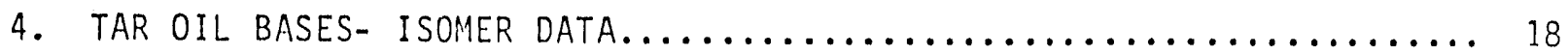

5. MATRIX FOR STUDYING EFFECTS OF TEMPERATURE AND PRESSURE IN FIRST-STAGE PROCESSING TO REMOVE HETEROATOMS ................ 19 


\section{LIST OF FIGURES}

Title

Page

1. Cumulative volume\% vs. temperature in ${ }^{\circ} \mathrm{C}\left({ }^{\circ} \mathrm{F}\right)$ for ERC tar oil

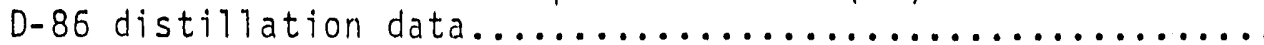

2. Cumulative volume\% vs. temperature in ${ }^{\circ} \mathrm{C}\left({ }^{\circ} \mathrm{F}\right)$ for $A N G$ tar $0 i 1$, WRI tar $0 i 1$, and ERC tar $0 i 1$ D-86 distillation data.............. 4

3. Cumulative GC area\% vs. temperature in ${ }^{0} \mathrm{C}\left({ }^{\circ} \mathrm{F}\right)$ for tar $0 \mathrm{il}$, tar $0 i 1$ polar, and tar $0 i l$ aromatic fractions..................... 7

4. Cumulative GC area\% vs. temperature in ${ }^{\circ} \mathrm{C}\left({ }^{\circ} \mathrm{F}\right)$ for tar $0 i 1$ and tar oil aliphatic fraction................................ 9

5. Cumulative GC area\% vs. temperature in ${ }^{\circ} \mathrm{C}\left({ }^{\circ} \mathrm{F}\right)$ for tar $0 \mathrm{il}$, tar $0 i 1$ acids, and tar $0 i 1$ neutral fractions..................... 10

6. Cumulative GC area\% vs. temperature in ${ }^{\circ} \mathrm{C}\left({ }^{\circ} \mathrm{F}\right)$ for tar $0 i 1$ and

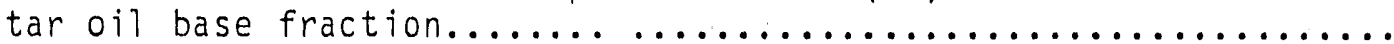


FEASIBILITY OF PRODUCING JET FUEL FROM GPGP BY-PRODUCTS

\section{EXECUTIVE SUMMARY}

The tar oil stream has the greatest potential to be used as a jet fuel feedstock which warrants its detailed analysis. The oxygenated compounds present comprise about 36 wt\% of this stream and are mainly phenolics such as phenol, methoxyphenol, naphthol, and their alkylated derivatives. However, non-polar oxygenated compounds such as dibenzofuran and its alkylated derivatives are also present. Basic compounds present in the tar oil (a minimum of 2.5 wt\%) contain nitrogen and include mainly quinolines but pyridines and anilines as well. Aliphatics (a minimum of 8 wt\%) are primarily norinal alkanes ranging from C11 to C30. The aromatics (at least 48 wt\%) are mostly naphthalene and its alkylated derivatives. However, phenanthrenes, fluorenes, and pyrenes are also present.

In the reaction investigation research, a test matrix has been designed for use in first stage data collection. Shell 424 catalyst will be used as the catalyst, ard the ranges of temperature and pressure that will be evaluated are $622-728^{\circ} \mathrm{F}$ and $1500-2500$ psig, respectively. 


\section{FEASIBILITY OF PRODUCING JET FUEL FROM GPGP BY-PRODUCTS Quarterly Technical Progress Report for the Period May 17-August 16, 1987}

\subsection{GOALS AND OBJECTIVES}

It is the goal of the national energy policy to foster an adequate supply of energy at reasonable cost. Domestic production supplies approximately $60 \%$ of the United States' petroleum requirements. However, domestic and world supplies have been and will continue to be unreliable in the future. Continued dependence upon foreign suppliers of crude oil could seriously affect our nation's economy as well as jeopardize our national security. As such, synthetic liquid fuels are an essential part of an energy scenario which provides the United States with a means to reduce reliance on imported $0 i 1$.

The Department of Defense (DOD) is the largest single consumer of liquid fuels in the United States, accounting for $2.7 \%$ of the nation's petroleum demand. Approximately one-half of the DOD requirements of Grade JP-7 turbine fuel, or 240,000 barrels, are consumed daily by the Air Force for aircraft operations. JP-4 is a naphtha-based fuel used primarily in the United States, while JP-8 is a kerosene-type fuel which is used abroad. Because of the need to assure adequate supplies of both types of turbine fuel at acceptable costs, the Air Force has investigated the characteristics, cost, and yield of these fuels. When produced from tar sands, shale oil, and heavy oils, and is seeking similar data for coal-derived liquids.

One producer of coal-derived liquids is the Great Plains Gasification Plant (GPGP) in Beulah, North Dakota. The plant, which is located near several Air Force bases along the northern tier, currently produces over 137 million cubic feet per day of high-Btu synthetic natural gas (SNG) from North Dakota lignite. In addition, the plant generates three liquid streams: naphtha, crude phenol, and tar oil. The naphtha may be directly marketable because of its low boiling point and high aromatic content. The other two streams, totalling approximately 4,300 barrels per day, are available as potential sources of aviation jet fuel for the Air Force. Aviation fuels produced from the Great Plains liquids could become an indigenous fuel supply for the northern tier bases. Minot Air Force Base at Minot, North Dakota, is remote from jet fuel supplies and would benefit from this development if the jet fuel produced at Great Plains can meet all specifications and be cost competitive with other suppliers.

The primary objective of this project is to assess the technical and economic feasibility of producing aviation turbine fuel from the by-product streams of GPGP. These streams, as well as fractions thereof, will be characterized and subsequently processed over a wide range of process conditions. The chemical and physical characteristics of the resulting turbine fuel products will be compared to petroleum-based fuels to determine their ability to meet military specification requirements.

A second objective is to assess the conversion of the by-product streams into a new, higher-density aviation fuel. Since no performance specifications currently exist for a high-density jet fuel, reaction intermediates and products will only be characterized to indicate the feasibility of producing such a fuel. 


\subsection{TASK 1 - FEED STOCK CHARACTERIZATION}

The tar oil, phenolic, and naphtha streams of the Great plains Gasification Plant (GPGP) are being characterized to assess their potential for up-grading to JP4 or 8 or to other valuable by-products. In the FebruaryMay Quarterly Report, information concerning the analysis techniques and their results were presented. This report continues that discussion by providing additional information concerning the tar oil stream with an emphasis on oxygen and nitrogen containing compounds.

The oxygenated compounds were successfully concentrated from the total tar oil using short column chromatography (tar polars fraction) or base extraction (tar acids fraction) techniques. Nitrogen-containing compounds were isolated using an acid ( $\mathrm{HCl}$ ) extraction technique (tar base fraction). Analysis of the concentrated samples provide more detailed information on compounds and compound types present in the total tar oil sample, and a method is being developed to improve the accuracy of determination of concentrations in the total sample. The data are being collected in a data base, and a data reduction package has been developed to enable correlaticns to be made. The use of addition and/or subtraction subroutines on comprehensive gas chromatographic (GC) data of the total sample and its fractions will enable mass balancing and the development of more representative data on the GPGP streams. Results of correlations made with simplified plotting techniques are presented in this report and will be extensively used in the topical report on the characterization work.

\subsection{Tar 0il Stream}

The tar oil stream has the greatest potential to be used as a feedstock to produce jet fuel. However, it is a thermally unstable material containing a myriad of compounds. The tar oil compounds have been separated into four compound types to provide more information: aliphatics, aromatics or neutrals, polars or acids, and bases. The wt\% of ecich compound type or fraction in the tota? tar oil has been determined. Nuclear magnetic resonance (NMR), and GC-MS (gas chromatography-mass spectrometry) techniques have been used to provide detail as to what compounds, and at what concentration, are present in the fractions. Elemental analysis on the total sample and each fraction enable mass balancing to be performed.

\subsubsection{Thermal Stability and Distillation}

Evaluation of simple ASTM D86 distillation data demonstrates the thermal instability of the tar oils. As depicted in Figure 1, the distillation curves and corresponding final boiling point can vary dramatically. The primary factor affecting this variability is the rate of heating of the sample. Figure 2 depicts data from different laboratories (average data from ANG Coal Gasification Company, Western Research Institute, and the UND Energy Research Center) for D86 data.

\subsubsection{Short-Column Fractions}

Short-column chromatography separation involves the eluting of aliphatics with pentane and isooctane, aromatics with methylene chloride, and polars with methanol from a highly activated silica gel column on which the total sample 


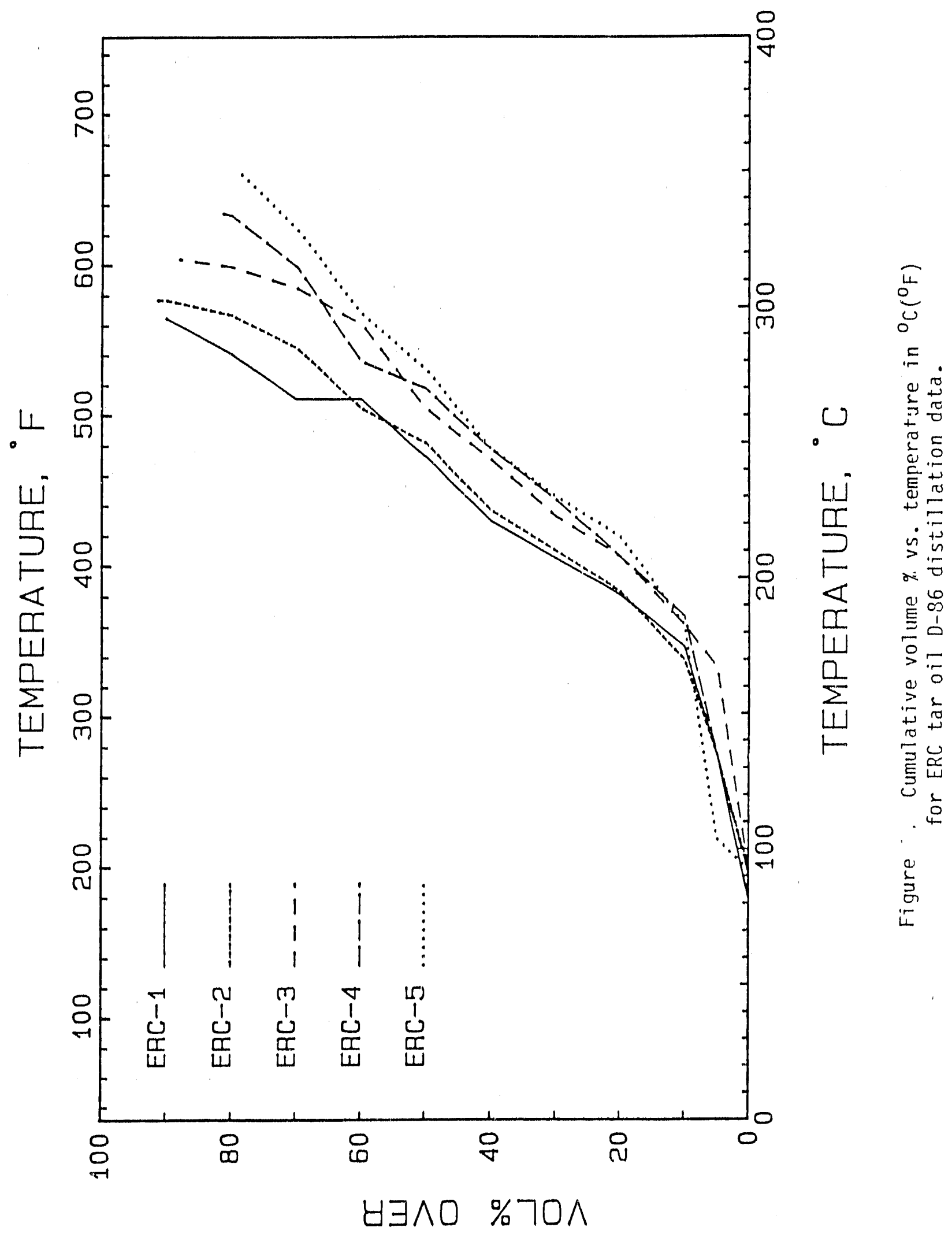




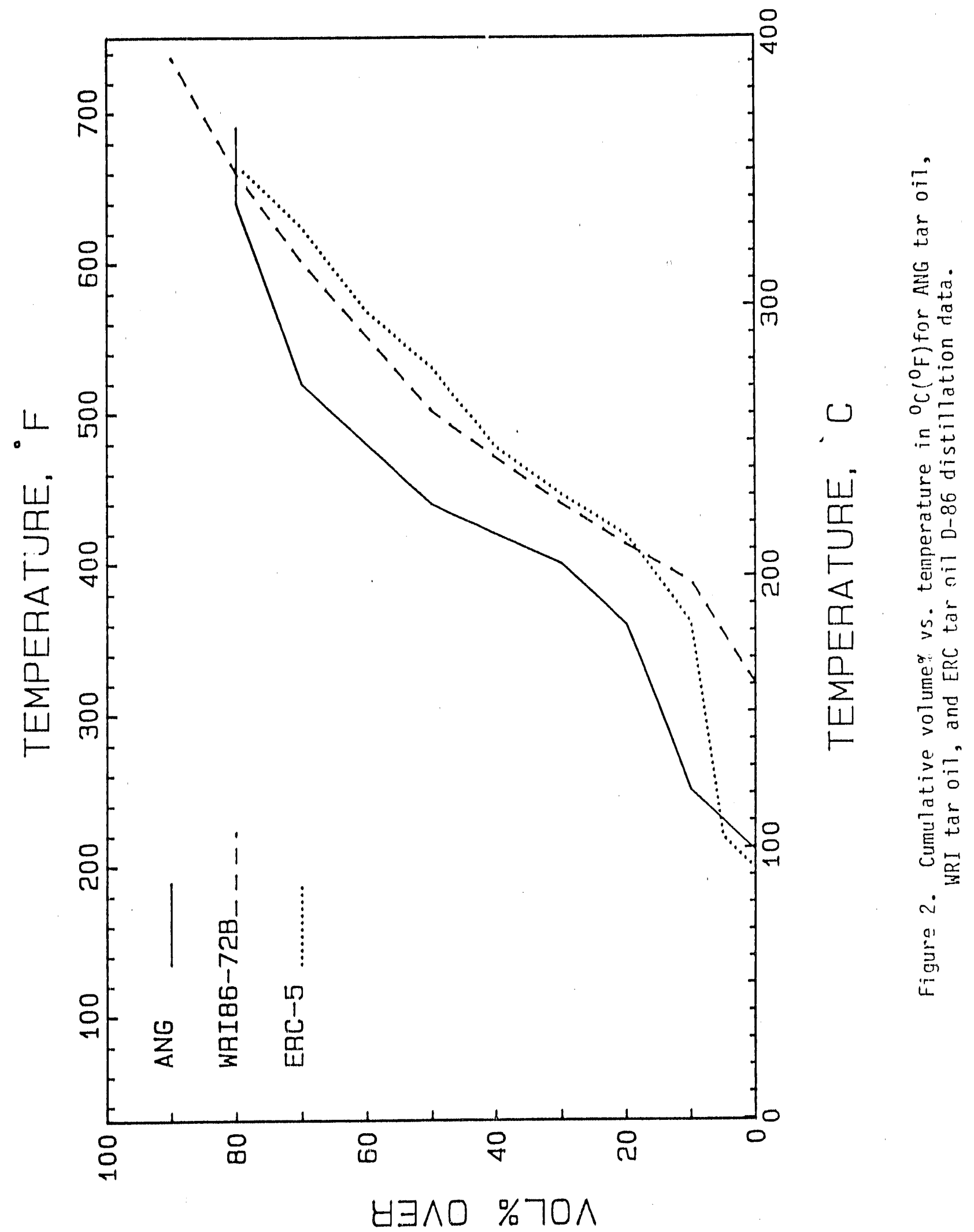


had been adsorbed (discussed last quarter). Table 1 presents the elemental data for the total tar oil sample and for the colurn fractions. The overall recovery was $92.4 \%$ of the moisture free (mf) organics charged. Water and some organics are irreversibly adsorbed on silica gel, and lighter organics are lost during the removal of eluting solvent under vacuum by rotary evaporation. Carbon and hydrogen recoveries were simfiar, 89\%, and the error is magnified in the oxygen by difference value. Nitrogen values have not been corrected to take into account the high blank value of 0.1 to 0.2 wt\% which was obtained cluring analysis. However, the high nitrogen content in the polars was expected, since many nitrogen compounds are highly polar. The high oxygen content in the polar fractions is due to the presence of phenolics, while in the aromatic fraction the oxygen content is due to dibenzofurans. The aliphatic fraction contains the highest hydrogen content but is also the smallest fraction.

NMR spectra of the various fractions were presented last quarter (Figure 2-11). Table 2 presents the proton distribution data as percent of total hydrogen observed for hydrogen in different structural units, and also iridicates that recoveries (or mass balances) are satisfactory (data from Table 1 is included in the calculations). The aliphatic fraction exhibits a high concentration of aliphatic and methyl protons. In the aromatic fraction, the presence of alkyl-aromatic groups is shown by the high $H$-alpha value of 32.1. A lower $\mathrm{H}$ in $\mathrm{CH}_{3}$ value indicates the average chain length of the alkyl groups is moderate. The H-Beta value of $5.6 \%$ indicates the potential presence of tetralin-like hydrogenated aromatics. Hydrocarbon portions of the molecular structure of the polar fraction contain mainly aromatics with methyl side chains.

Figure 3 depicts the difference between the total tar oil sample and the aromatic and polar fractions using GC data. The vertical axis is in cumulative area\% of sequentially eluting compounds from a GC column (described last quarter). The horizontal axis is the eluting temperature of the compound. As will be seen, the use of these profiles provides more detail in that compounds that are higher in concentration are readily noticed. The compounds were identifled by MS and often more than one isomer or compound with the same elemental composition was present.

In Figure 3 for the polar fraction (36 wt\%), the compounds causing the area\% increases at about $190^{\circ} \mathrm{C}$ are C1-phenols ( 5 and 12 area\%). C2-phenols are present at $210^{\circ} \mathrm{C}$. Various alkylated naphthols are present around $170^{\circ} \mathrm{C}$. In general most of the polar fraction consists of the various isomers of alkylated phenols and naphthols. Small amounts of methoxyphenols are also present.

The aromatic fraction ( $48 \mathrm{wt} \%$ ) shows the highest concentration of naphthalene ( 8 area\%) and alkylated naphthalenes. Smaller amounts of indans and indenes are present. Three ring aromatics such as fluorene (2 area\%), phenanthrene ( 3 area\%), pyrene $(2$ area\%) and their alkylated derivatives are eluted at higher temperatures. Dibenzofuran $(3$ area\%), and its alkylated derivatives, are the major oxygenated compounds in the aromatic fraction. In comparison to the total tar oil sample, the polars are found more often at lower temperatures while the aromatics are found in the higher temperature regions. 
TABLE 1

ELEMENTAL ANALYSIS OF TAR OIL TOTAL. AND COLUMN FRACTIONS

\begin{tabular}{|c|c|c|c|c|c|c|c|}
\hline Fraction & $\begin{array}{c}\text { Fraction } \\
(\text { wt } \%)\end{array}$ & C. & $\begin{array}{c}\text { Elemental } \\
H\end{array}$ & $\underset{N}{\text { Compos }}$ & $\begin{array}{c}\text { ition } \\
\text { S }\end{array}$ & $\begin{array}{l}(w t \%) \\
0+S^{c}\end{array}$ & $\begin{array}{c}\text { Karl Fischer } \\
\text { water }\end{array}$ \\
\hline $\begin{array}{r}\text { Total, } A R^{a} \\
m f^{b}\end{array}$ & $\begin{array}{r}100.0 \\
98.8\end{array}$ & $\begin{array}{l}83.76 \\
84.78\end{array}$ & $\begin{array}{l}8.83 \\
8.80\end{array}$ & $\begin{array}{l}0.52 \\
0.53\end{array}$ & $\begin{array}{l}0.39 \\
0.39\end{array}$ & $\begin{array}{l}6.89 \\
5.89\end{array}$ & 1.20 \\
\hline $\begin{array}{l}\text { Aliphatic } \\
\text { Aromatic } \\
\text { Polar }\end{array}$ & $\begin{array}{r}7 . ! \\
47 . \% \\
35.9\end{array}$ & $\begin{array}{l}85 . ? .4 \\
88.82 \\
75.46\end{array}$ & $\begin{array}{r}14.66 \\
8.36 \\
7.62\end{array}$ & $\begin{array}{l}0.11 \\
0.20 \\
0.85\end{array}$ & & $\begin{array}{r}0.00 \\
2.62 \\
16.07\end{array}$ & \\
\hline Recovery & 92.4 & 89.69 & 89.36 & 77.41 & & 118.5 & \\
\hline
\end{tabular}

TABLE 2

HYDROGEN DISTRIBUTION NMR ANALYSIS OF TAR OIL COLUMN FRACTIONS

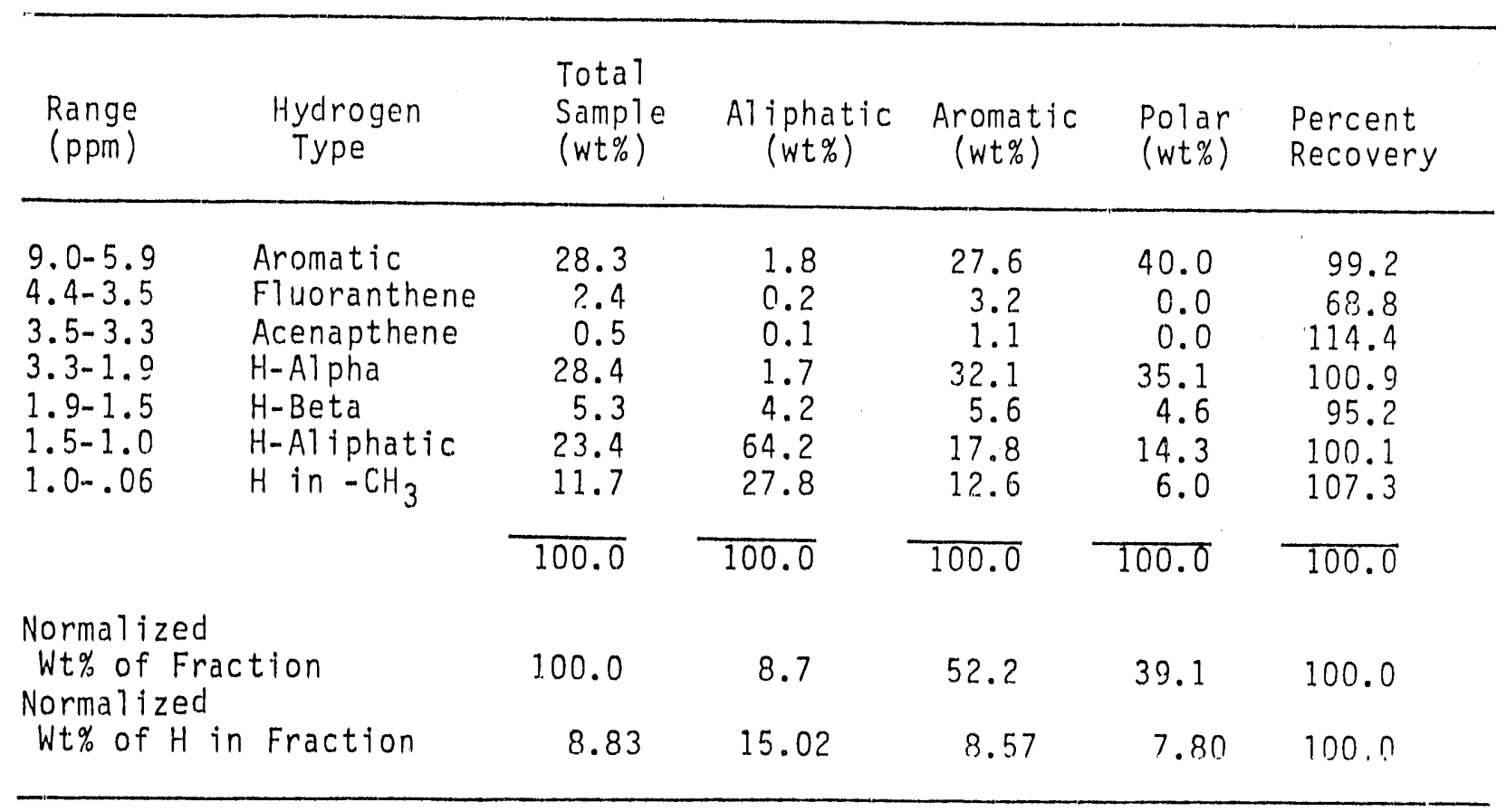




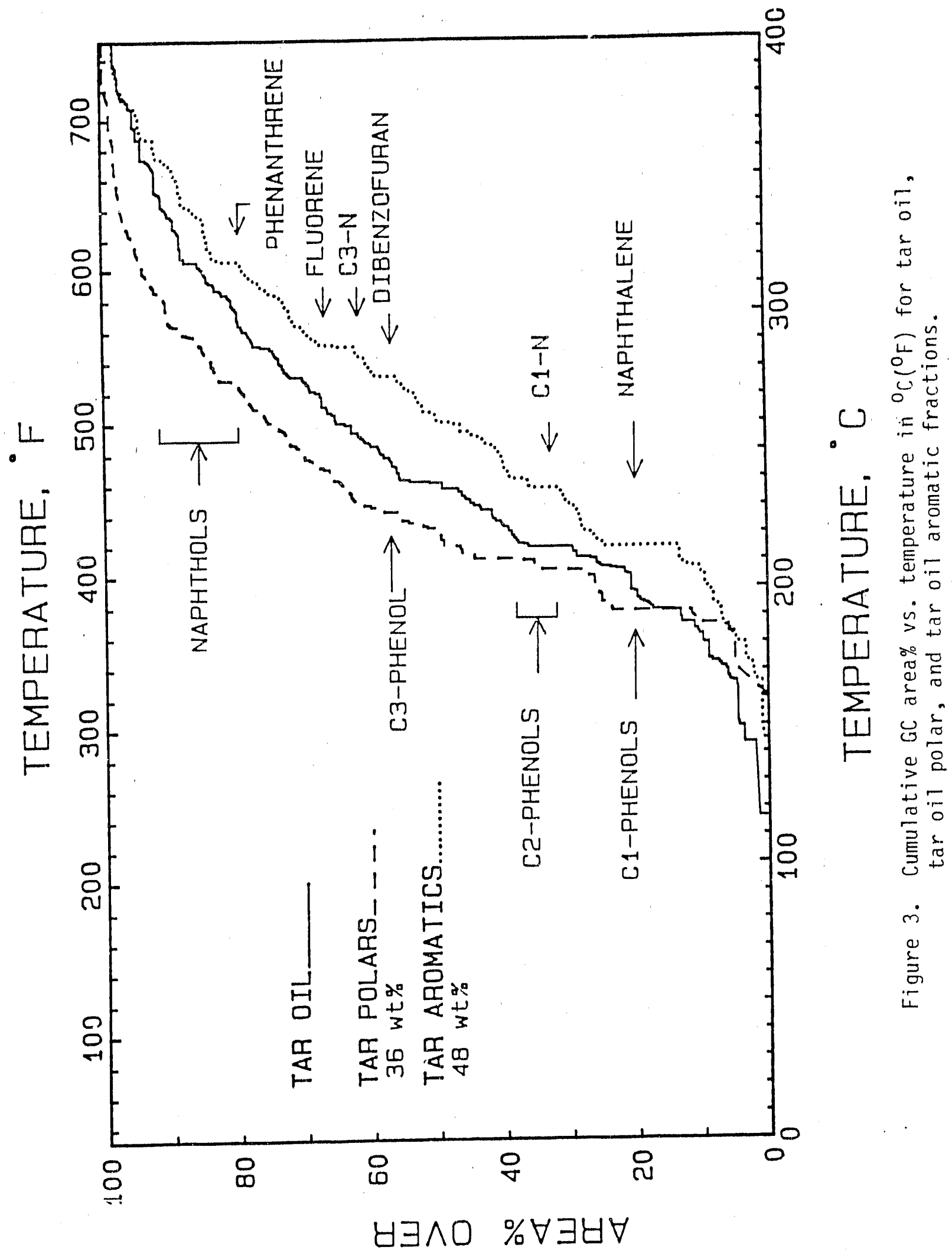


Figure 4 compares the tar oil to the aliphatic fraction (8wt\%). The step increases caused by normal alkanes from C11 at $196^{\circ} \mathrm{C}$ to $\mathrm{C} 24$ at $391^{\circ} \mathrm{C}$ are readily apparent. Lower boiling alkanes would probably be lost during vacuum evaporation to remove pentane solvent and would be lost during the removal of octane solvent. Higher boiling normal alkanes up to $\mathrm{C} 30$ were present in this fraction. The low concentration of the aliphatic fraction in the tar oil obscures observing the alkane steps in the GC area\% profile.

A computer subroutine is being prepared to correlate the total and fractional GC data, enabling mass balancing to be made in order to develop a more accurate picture of the tar oil stream. This will enable the prediction of potential end uses.

\subsubsection{Acid-Base Neutral Fractions}

Acid (28 wi\%), base (2.5 wt $)$, and neutral (48 wt $\%$ ) fractions were prepared by sequential extraction of a tar oil-pentane solution with aqueous base $(\mathrm{NaOH})$, aqueous acid $(\mathrm{HCl})$, and removing the pentane under vacuum, respectively. The closure was low at $79 \%$. Figure 5 depicts the $6 C$ data for comparison to the acid and neutral fractions with each other and with the total tar oil. The plots shown in this figure are virtually identical to those shown in Figure 3 , indicating the close similarity of these extraction and column fractions. However, the neutral fraction obtained by extraction does contain normal alkanes which are present in the aromatic fraction obtained by column separation. A fraction of major interest is the base fraction composed of nitrogen-containing compounds found in higher boiling regions, which is also seen in figure 6. Table 3 presents detailed data on the GC-MS analysis of the base fraction. These data indicate that most individual compounds are present in small amounts even in this concentrated sample. Table 4 presents concentration data in area\% of this fraction for pyridine, quinoline, aniline, and their alkylated derivatives.

\subsection{TASK 2 - REACTION INVESTIGATIONS/PRODUCT ANALYSES}

\subsection{Staged Processing}

To produce quality jet fuel from coal-derived liquids, the content of oxygen-, sulfur-, and nitrogen-containing compounds, also called heteroatoms, must be reduced to virtually nil, while the aromatic rings must be saturated with hydrogen without destroying the ring structures. A survey was undertaker, to determine the most promising process, or combination of processes, which would produce these results. Of particular interest was the collection of information regarding suitable catalysts which might be used in this type of processing. The major results of the survey follow.

Currentiy, two different process approaches are taken. The first is a single-stage process in which heteroatom removal and subsequent hydrocracking and hydrogenation take place under high temperature/high pressure conditions. By varying the severity of the conditions, it is possible to controi the composition of the final product. This process is usually performed with a Ni-lu catalyst at temperatures of $680-720 \mathrm{~F}$ and pressures of 2000-2500 psig. Heteroatom concentration is reduced to less than $100 \mathrm{ppm}$ using this method. 


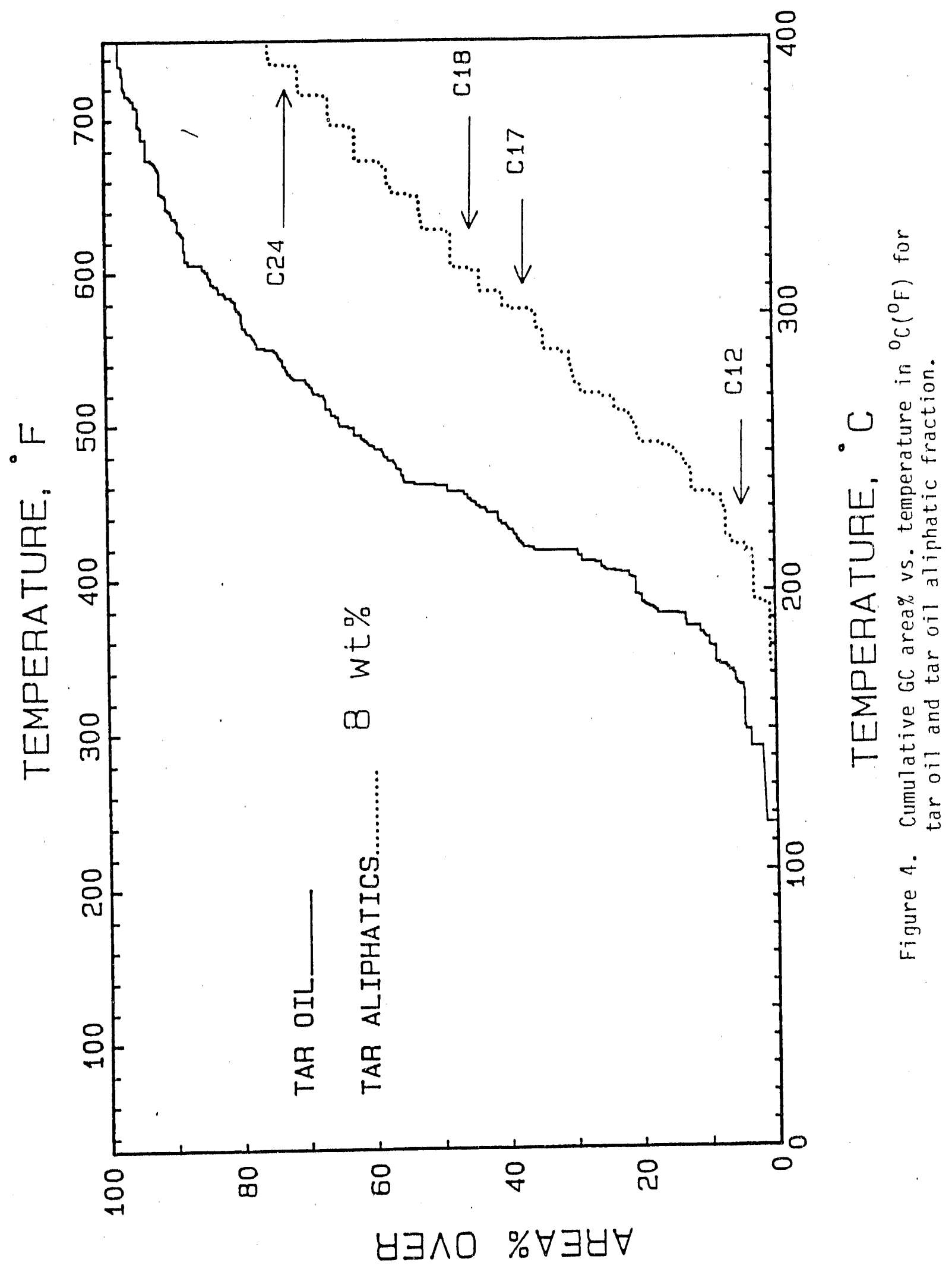




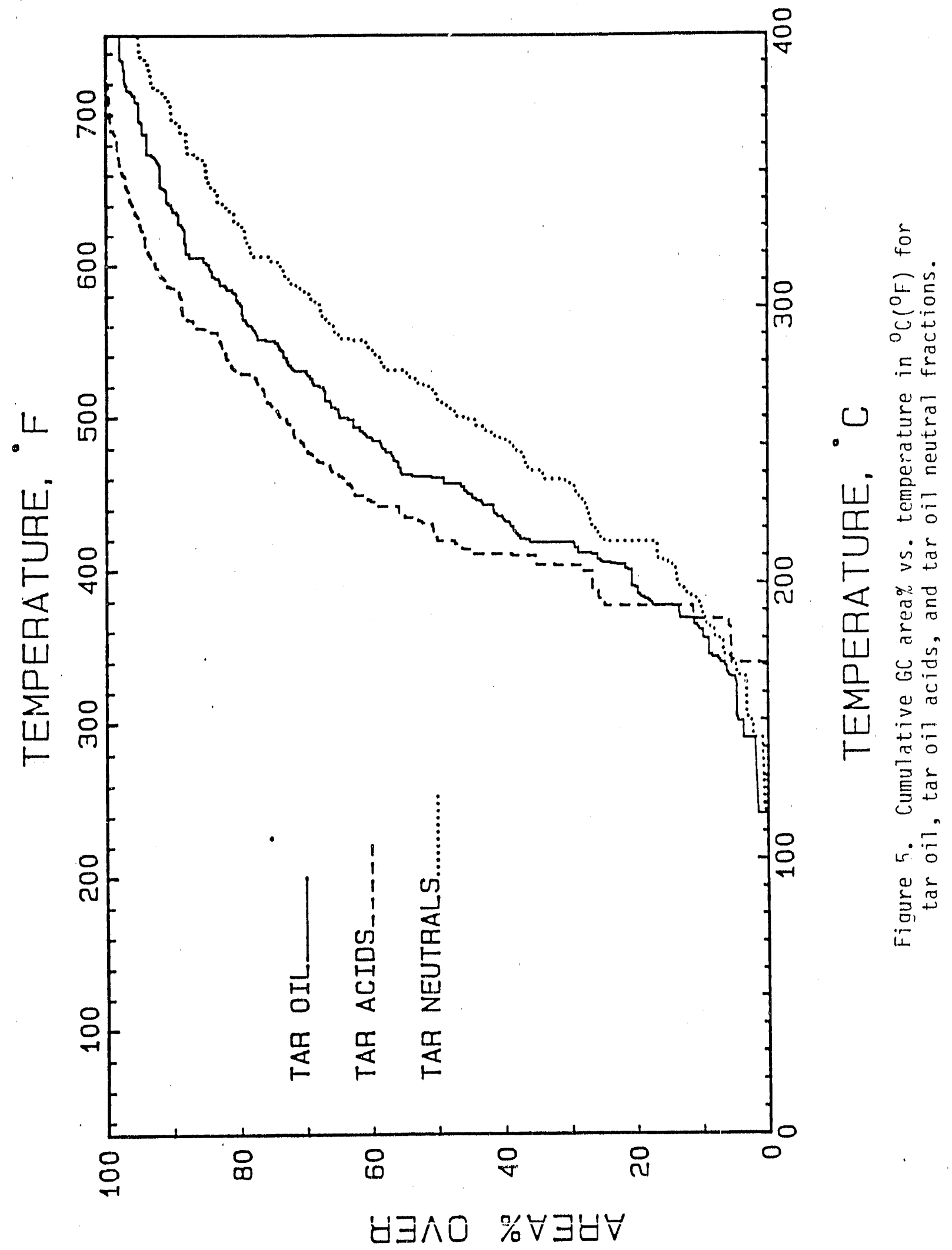




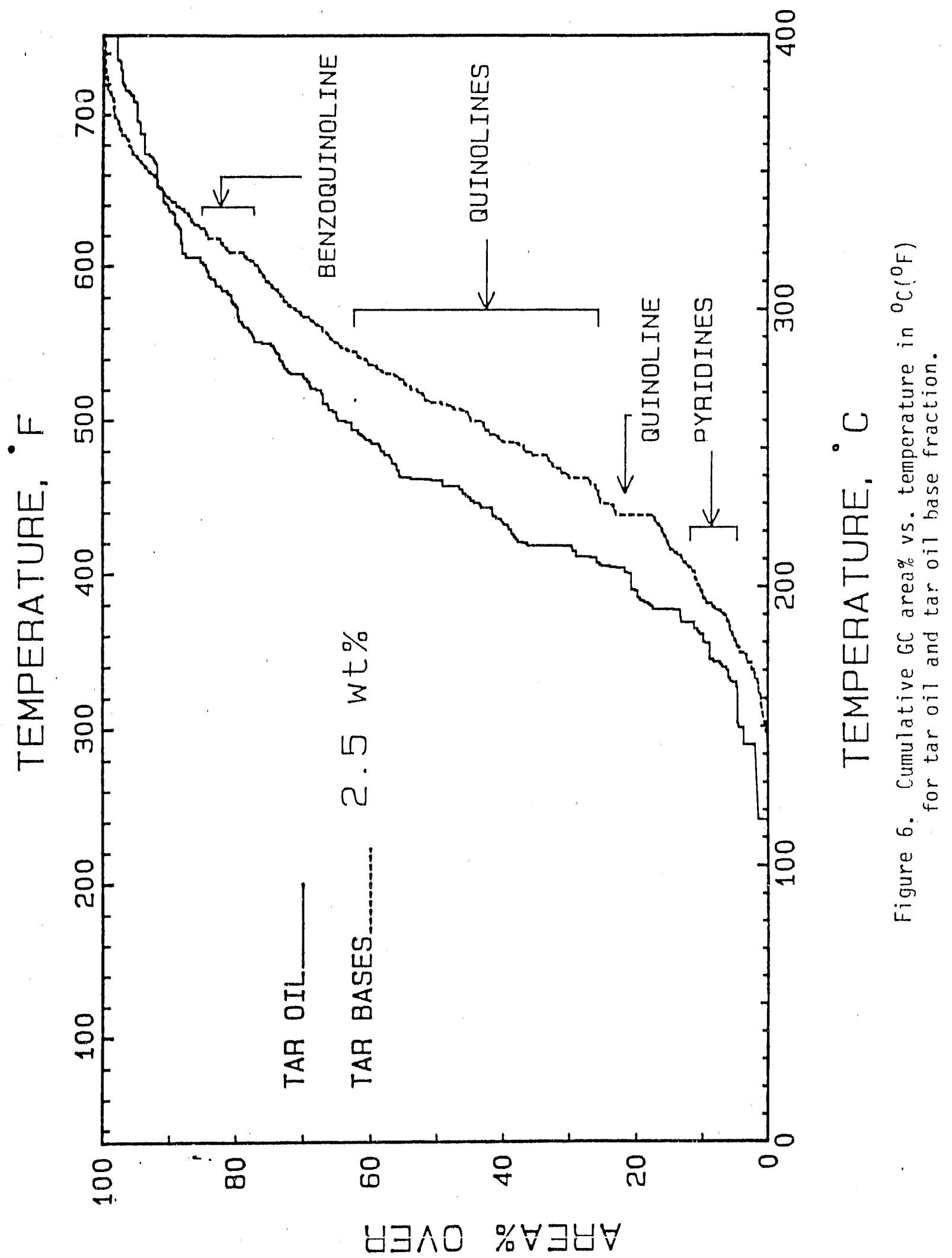


TABLE 3

TAR OIL BASES - COMPONENT DATA

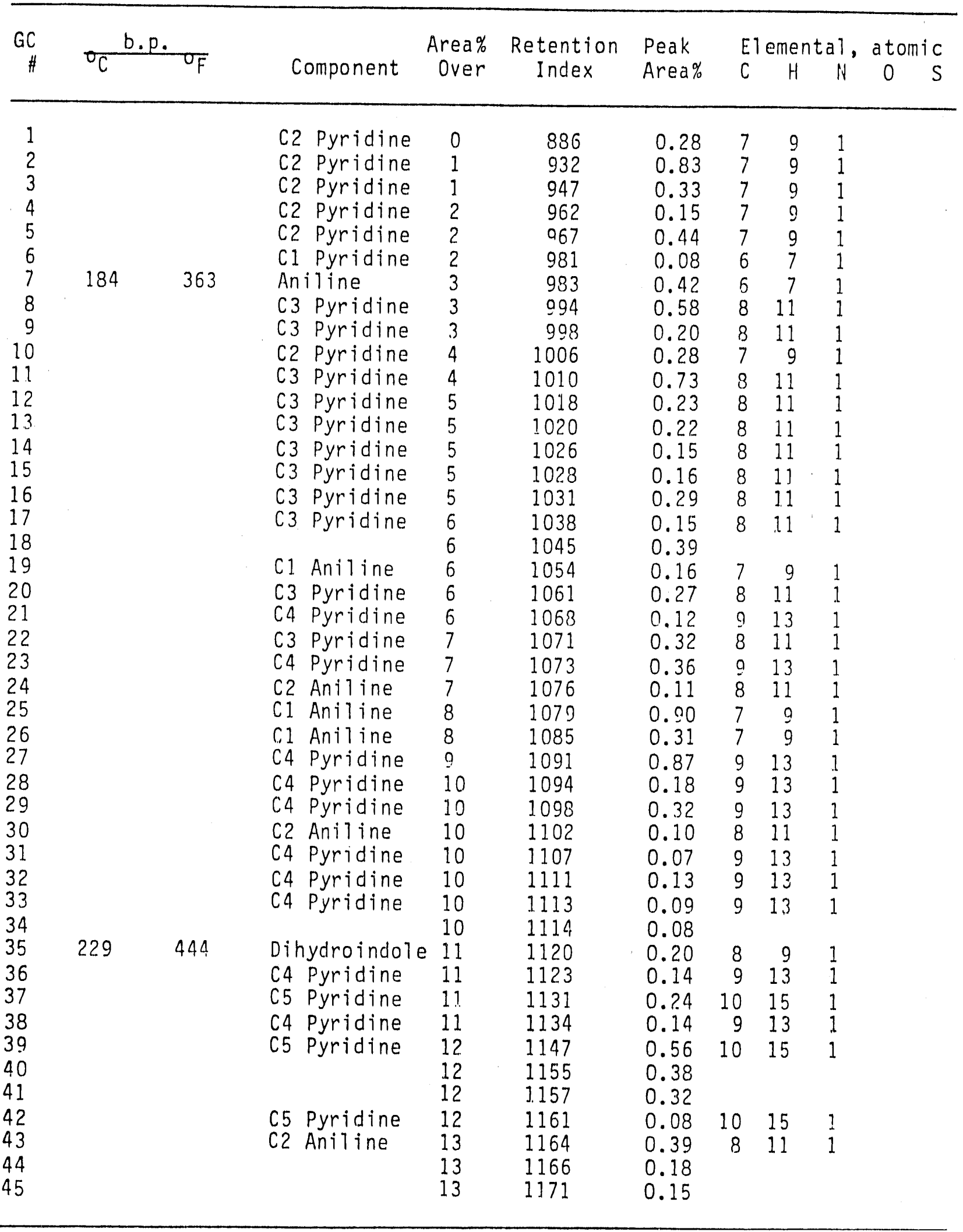


TABLE 3 CONTINUED

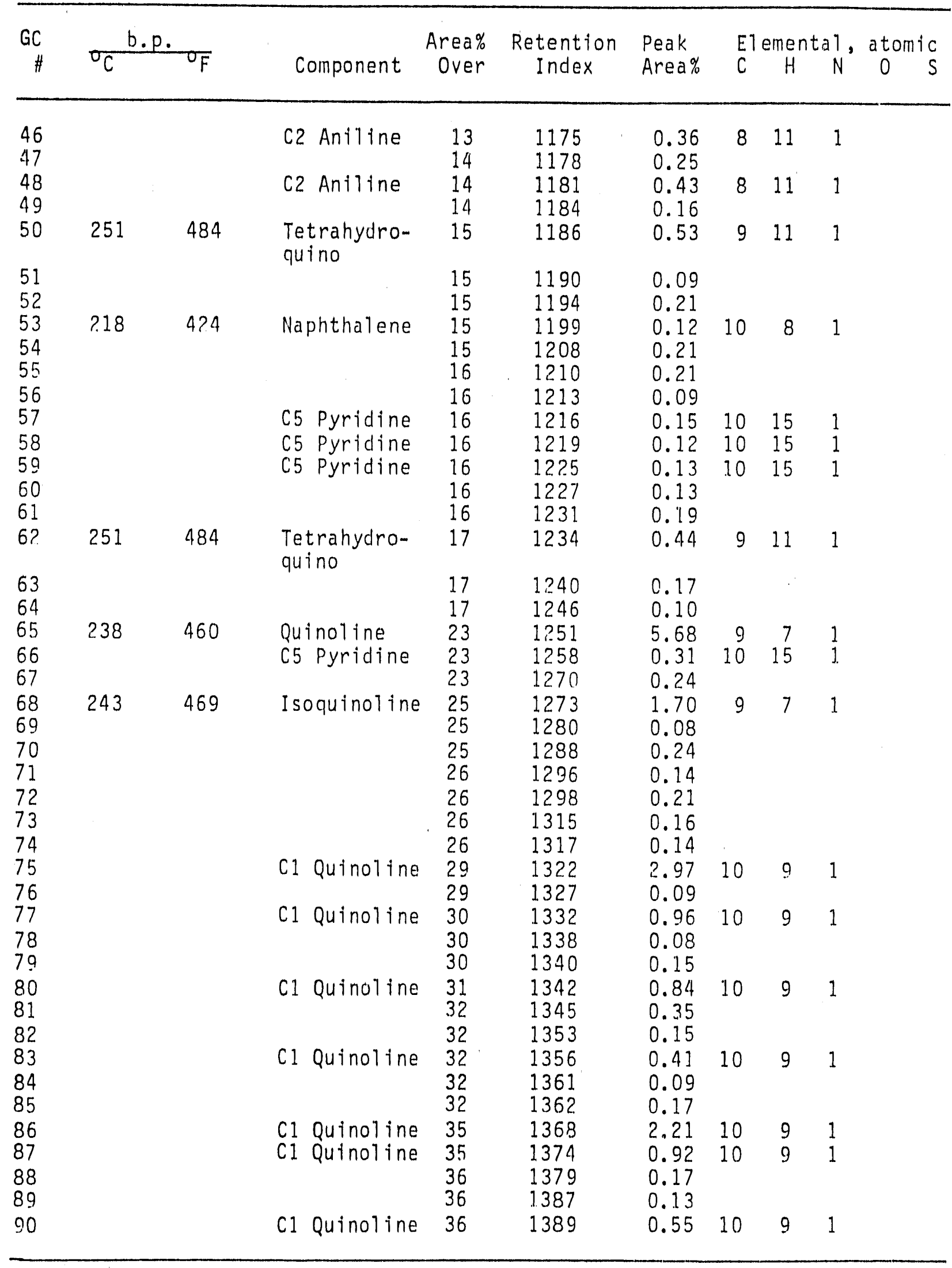


TABLE 3 CONTINUED

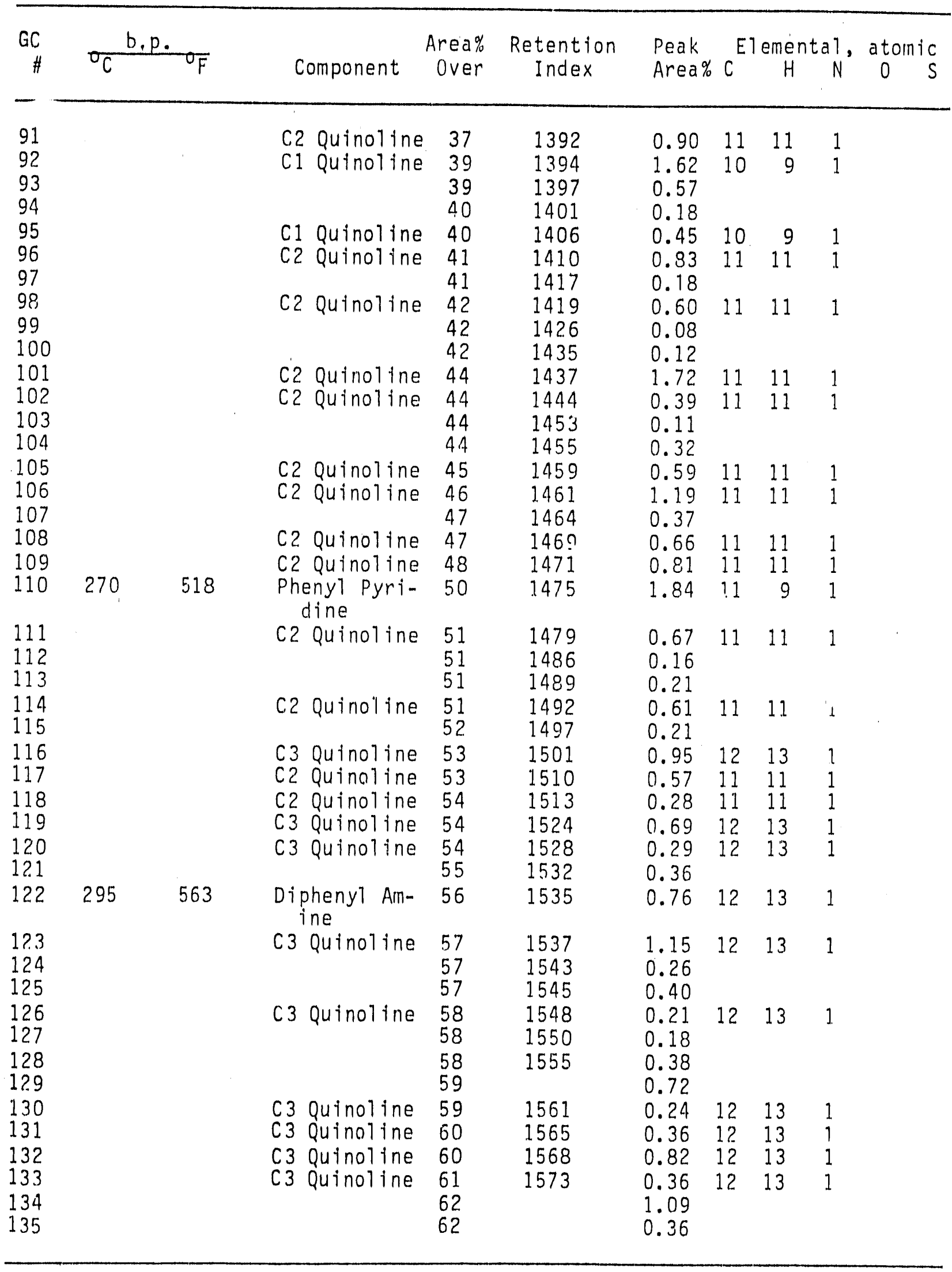


TABLE 3 CONTINUED

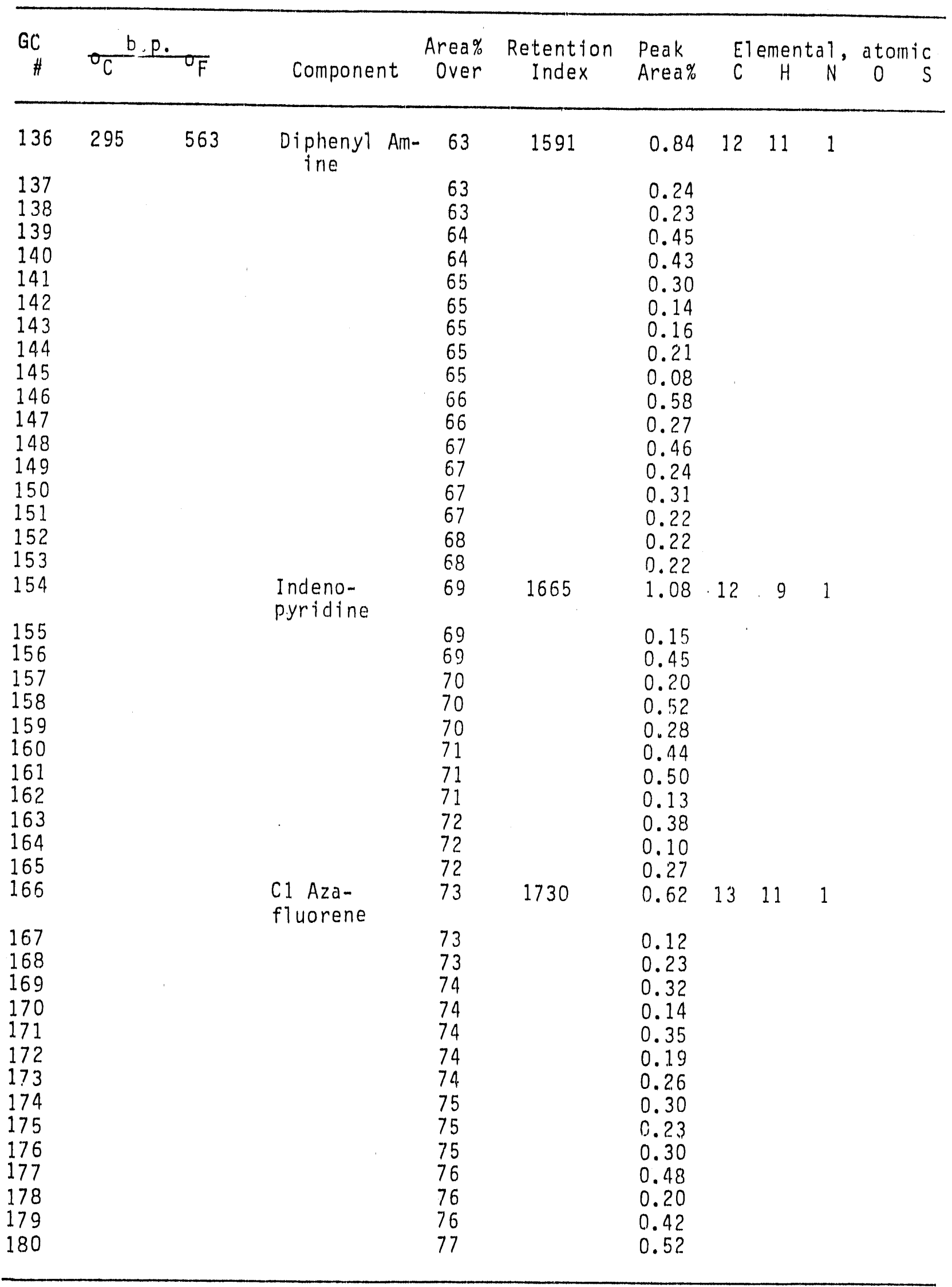


TABLE 3 CONTINUED

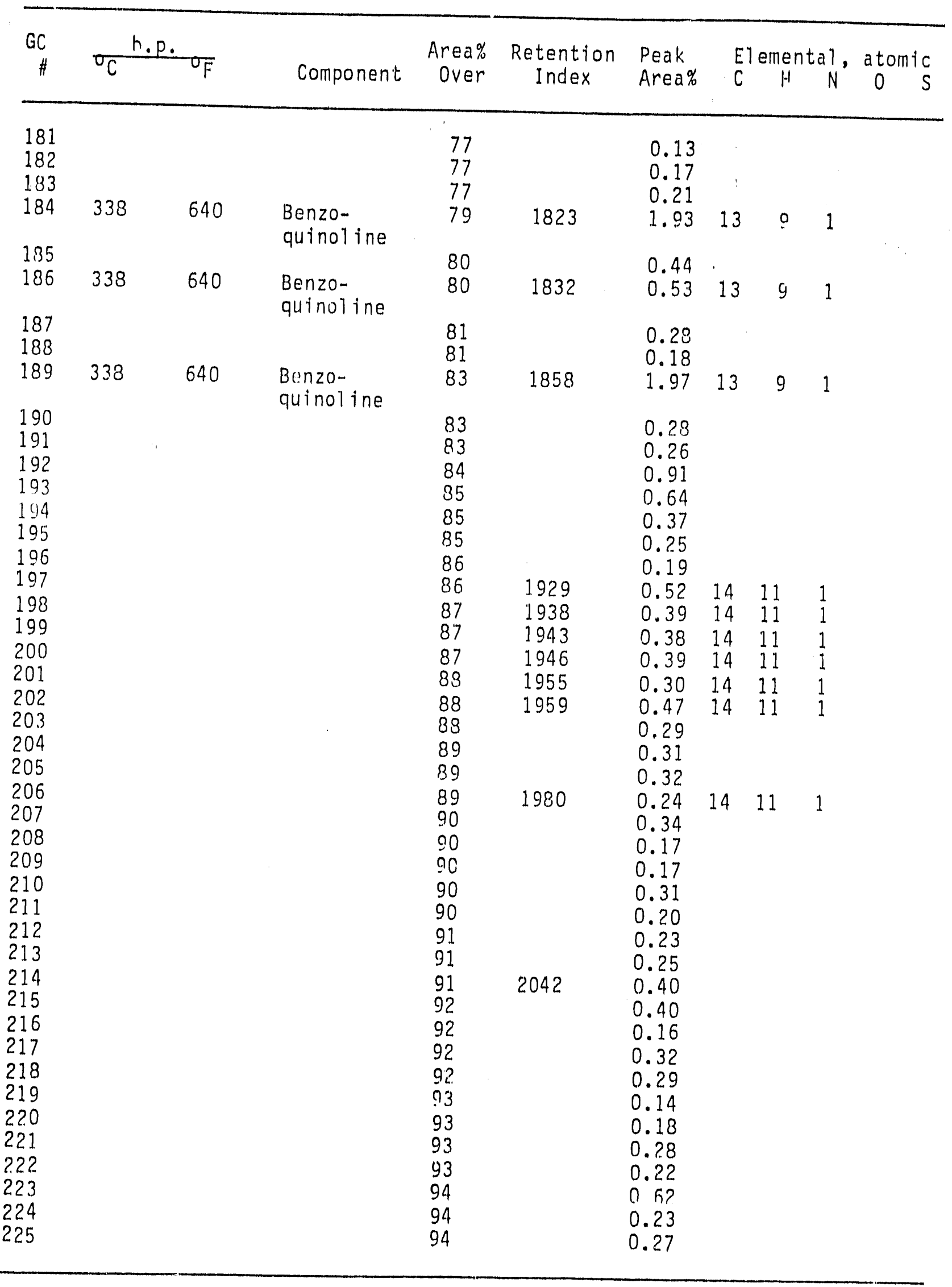


TABLE 3 CONTINUED

\begin{tabular}{|c|c|c|c|c|c|c|}
\hline GC & ${ }_{\sigma_{C}}$ b.p. ${ }_{\sigma_{F}}$ & Component & $\begin{array}{l}\text { Area\% } \\
\text { Over }\end{array}$ & $\begin{array}{l}\text { Retention } \\
\text { Index }\end{array}$ & $\begin{array}{l}\text { Peak } \\
\text { Area\% }\end{array}$ & $\begin{array}{l}\text { Elemental, atomic } \\
\mathrm{C} H \mathrm{~N}\end{array}$ \\
\hline $\begin{array}{l}226 \\
227 \\
228 \\
229 \\
230 \\
231 \\
232 \\
233 \\
234 \\
235 \\
236 \\
237 \\
238 \\
239 \\
240 \\
241 \\
242 \\
243 \\
244 \\
245 \\
246 \\
247 \\
248 \\
249 \\
250 \\
251\end{array}$ & & . & $\begin{array}{l}95 \\
95 \\
95 \\
95 \\
96 \\
96 \\
96 \\
96 \\
96 \\
97 \\
97 \\
97 \\
97 \\
97 \\
98 \\
98 \\
98 \\
98 \\
98 \\
98 \\
98 \\
99 \\
99 \\
99 \\
99 \\
99\end{array}$ & $\begin{array}{l}2209 \\
2273 \\
2289\end{array}$ & $\begin{array}{l}0.16 \\
0.38 \\
0.10 \\
0.39 \\
0.15 \\
0.17 \\
0.14 \\
0.12 \\
0.13 \\
0.37 \\
0.12 \\
0.11 \\
0.25 \\
0.14 \\
0.39 \\
0.09 \\
0.14 \\
0.08 \\
0.34 \\
0.11 \\
0.12 \\
0.16 \\
0.10 \\
0.10 \\
0.15 \\
0.13\end{array}$ & \\
\hline
\end{tabular}


TABLE 4

TAP. OIL BASES - ISOMER DATA

Pyrtdine

C1 Pyridine

C2 Pyridine

C3 Pyridine

C4 Pyrtdine

C5 Pyridine

Quinolitne

C1 Quinoline

C2 Quitnoline

C3 Quinoline

Benzoquinoline

TOTAL

Antline

C1 Antline

C2 Anlline

TOTAL

\begin{tabular}{rr}
0 & 0.00 \\
1 & 0.08 \\
6 & 2.31 \\
11 & 3.30 \\
10 & 2.42 \\
7 & 1.59 \\
\hline
\end{tabular}

35

9.70

5.68

10.93

8.97

5.07

4.43

35.08

0.42

1.37

1.39

TOTAL

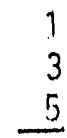

9
3.18

The second method employs a two-stage process. In the first, highseverity, stage, the heteroatoms are removed using commerclally-avallable catalysts. During this stage, nitrogen must be removed to concentrations of less than $10 \mathrm{ppm}$ in order not to poison the second-stage catalyst. The second stage is a low-severity stage in which a noble metal catalyst is employed to saturate the aromatic ring structure without destroying 1 t. With this system, it is posstble to obtain products which contain less than $5 \%$ aromatics.

At the University of North Dakota Energy Research Center (UNDERC), processing of the GPGP by-product streams is belng performed using a two-stage process in which removal of the heteroatoms takes place in the first stage and hydrogenation of the ring structures takes place in the second stage. To efficiently obtain the information required for determination of the "optimum" condltions necessary for heteroatom removal in the first stage processing, a statistical experinental design will be used. It is not expected that the heteroatom content of the product of the first stage will be a linear function of the temperature and pressure of the process. Therefore, a central 
composite destgn for two factors wlll be used to collect the experfmental data. This will allow the fitting of a general quadratic equation for smoothing and prediction. This class of design allows the experimenter to butld upon a two-level facturlal design and adds a set of axial polnts, which, together with a center point, allow the estimation of all pure quadratic terms.

Table 5 shows the matrix which has been deslgned for use in first-stage data collection. For these experiments, shell 424 will be used as the catalyst, and the ranges of temperature and pressure that will be evaluated will be $622-728^{\circ} \mathrm{F}$ and $1500-2500 \mathrm{ps} / \mathrm{g}$, respectively. Usually, five center point replications are performed with this type of analyis. Because the vartability of the equipment is known and can be factored in, only two center polnt replicaitions will be performed. The matrix will be randomized to ensure that all results are independent.

Following collection of the data, each response will be analyzed via computer regression analysis. The full model will be fit, and a check made for outlying data polnts. After a check is made for lack of fit of the quadratic equation, any unnecessary terms wlll be eliminated from the quadratic equation, and another check will be performed for lack of fit. predictions made from the resulting equaitons will be displayed via contour plots, and the predicted "best" run conditions wlll be determined. A final run will be made at these conditions to verlfy the results.

When the first-stage testing has been completed, second-stage testing will begin. It has not been decided which particular catalyst will be used in the second stage. One to two runs will be performed at catalyst-specific conditions to determine the effectiveness of the catalyst/conditions at hydrogenation without hydrocracking.

TABLE 5

MATRIX FOR STUDYING EFFECTS OF TEMPERATURE \& PRESSURE IN FIRST-STAGE PROCESSING TO REMOVE HETEROATONS

\begin{tabular}{cccc}
\hline Run & Temperature & $\frac{\text { Pressure }}{(\text { Psig) }}$ & \\
\hline 1 & 728 & 2500 & \\
2 & 728 & 1500 & factorial \\
3 & 622 & 2500 & points \\
4 & 622 & 1500 & \\
5 & 675 & 2710 & \\
6 & 675 & 1300 & star \\
7 & 750 & 2000 & points \\
8 & 600 & 2000 & \\
9 & 675 & 2000 & center \\
10 & 675 & 2000 & points
\end{tabular}




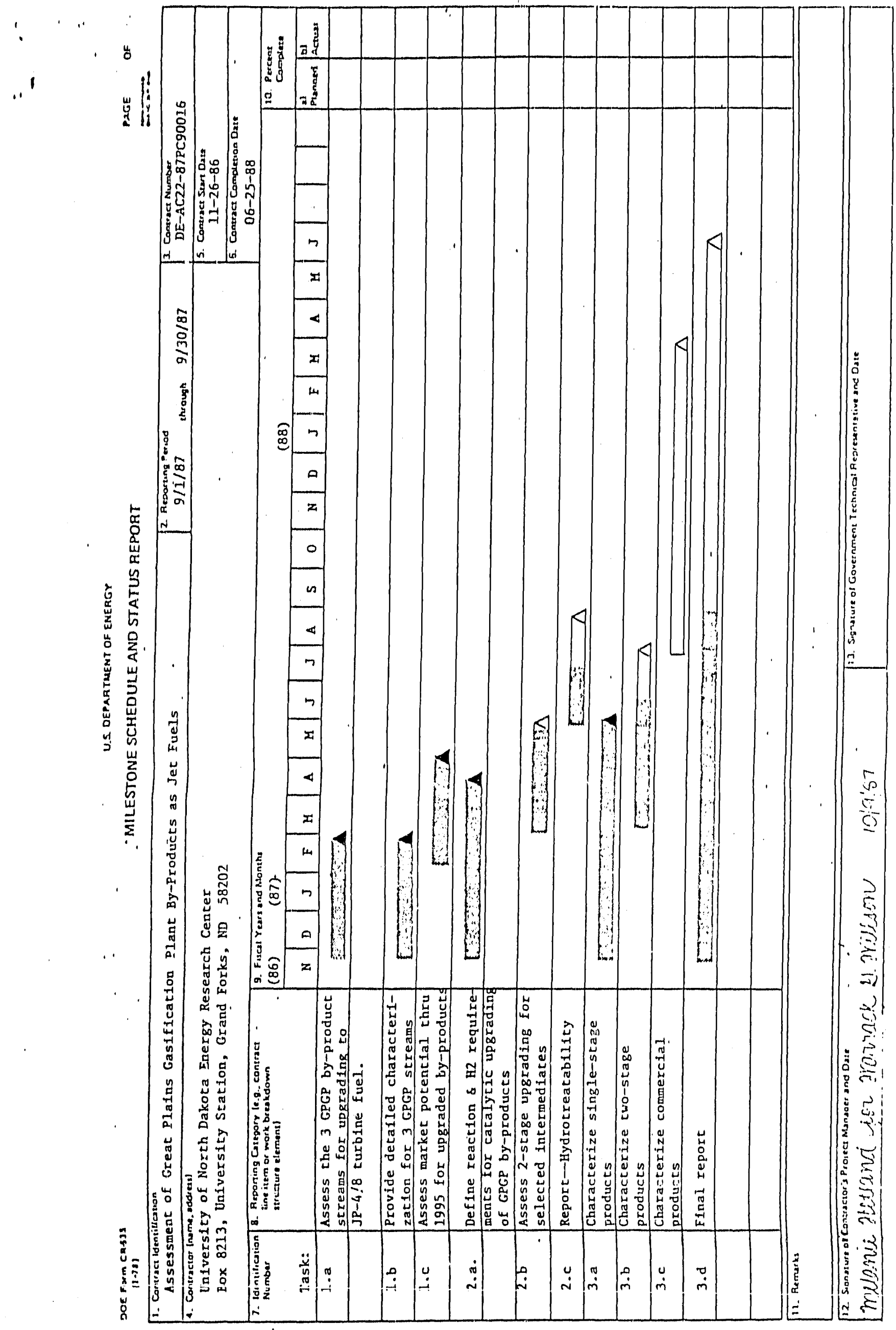




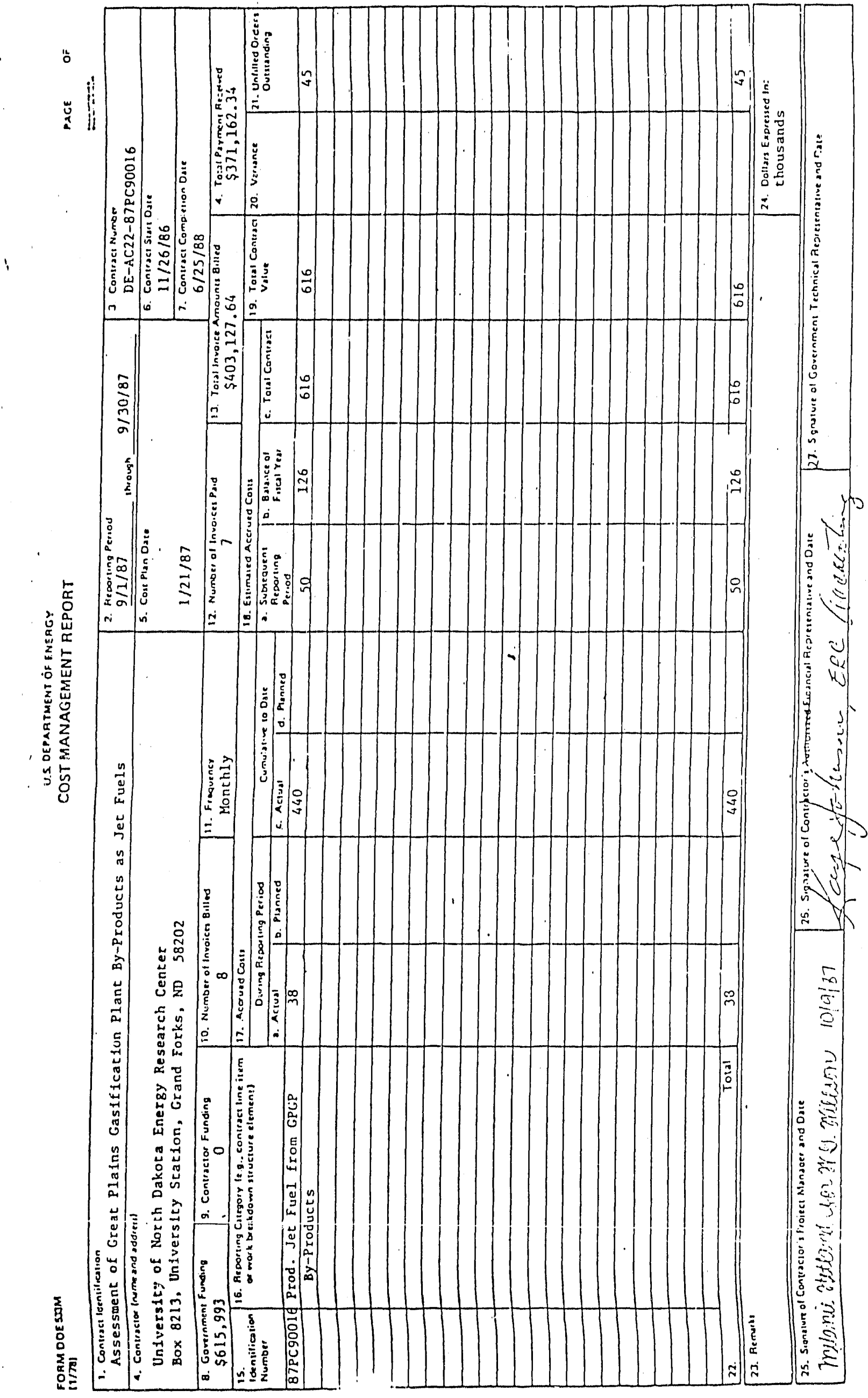



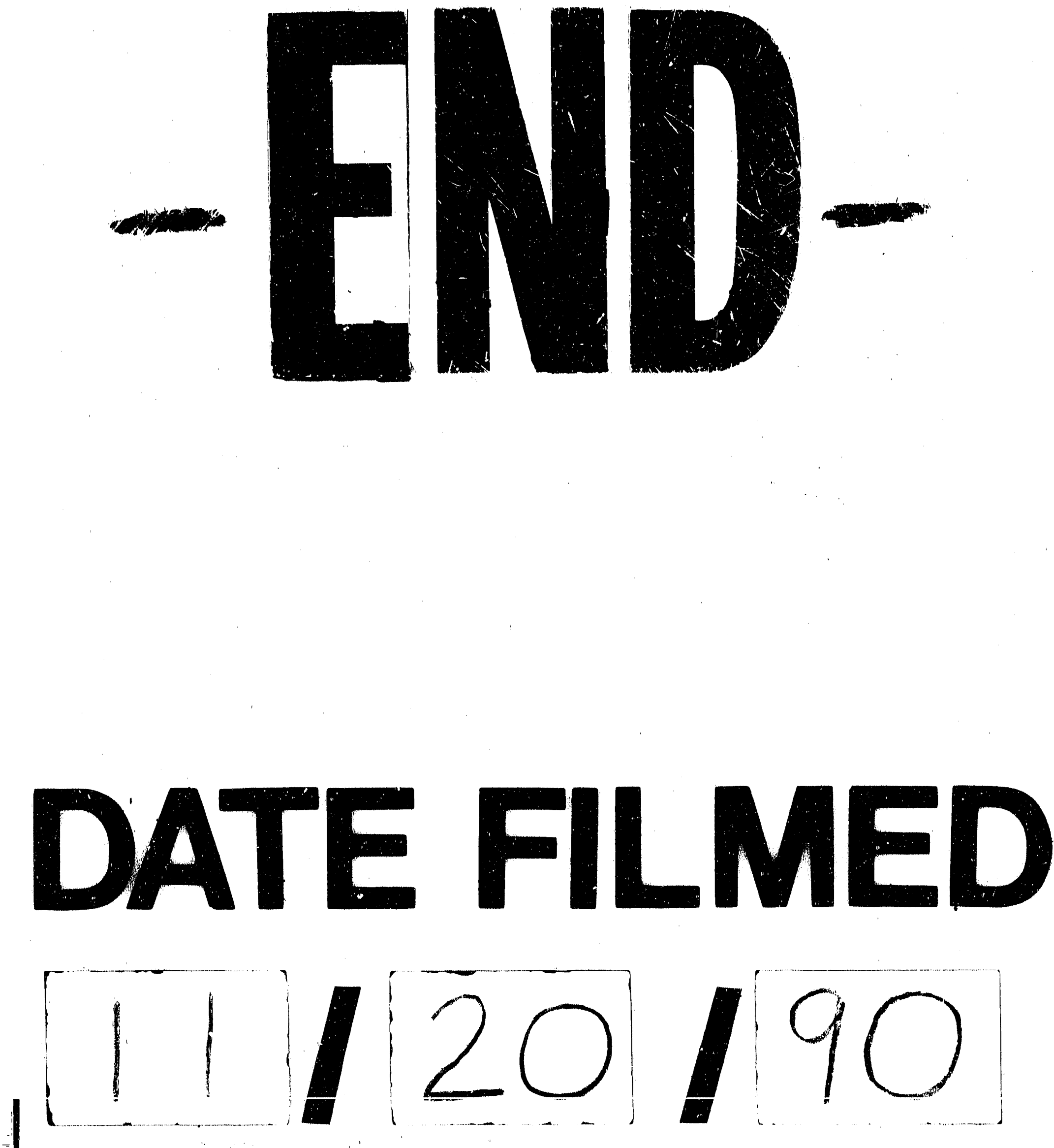
